\title{
Е.Н. Калиниченко
}

Аальневосточный федеральный университет Владивосток. Россия

\section{Использование видеоинформации в системе корпоративной коммуникации ВГУЭС}

\begin{abstract}
Статья посвящена вопросу обеспечения корпоративных интересов Владивостокского государственного университета экономики и сервиса (ВГУЭС) путем эффективного использования виАеоинформации в системе корпоративной коммуникации. Подобные Аействия позволят улучшить имиАж университета как одного из передовых вузов Приморья и максимально охватить все значимые Аля образовательного учрежАения аудиторные группы. Сегодня благоАаря развитию технологий расширяется круг организаций, имеющих корпоративное телевидение. ОАнако, несмотря на актуальность корпоративного телевидения, вопрос использования видеоинформации в системе корпоративной коммуникации все еще недостаточно изучен. Поскольку у видеоинформации есть свои особенности, имеет смысл говорить об этом.

Целью Аанного исслеАования является анализ использования видеоинформации в системе корпоративной коммуникации на примере ВГУЭС. Объект исследования - корпоративная коммуникация ВГУЭС, преАмет изучения - использование видеоинформации в корпоративной коммуникации ВГУЭС. АеАукция, наблюдение, сравнение, анализ, классификация и обобщение выбраны основными методами исследования. В результате анализ показал, что всю видеоинформацию вуз использует Аля информирования не только внутренней общественности, но и внешней. При создании видеоматериалов используют разнообразные аудиовизуальные среАства выразительности. Информация легко воспринимается зрителем, вызывает у него Аоверие и ощущение присутствия на месте события. Она успешно укрепляет имиАж университета, продвигает образовательные услуги, являясь важной, неотъемлемой и эффективной частью системы корпоративного информирования. ПреАпочтение отАается новостным сюжетам. ОАнако недочеты в организационной Аеятельности вуза влияют на работу корпоративного телевиАения и, как слеАствие, на максимально продуктивное использование видеоинформации. Аля повышения эффективности использования видеоинформации необходимо устранить Аанные проблемы; продумать, систематизировать и структурировать сетку вещания; разнообразить программную и жанровую палитры; Аобавить развлекательный сегмент. Аанные сведения могут быть использованы тележурналистами, PR-специалистами, стать базой курсовых и дипломных работ.
\end{abstract}

Ключевые слова и словосочетания: корпоративное телевидение, имиАж, коммуникации, использование виАеоинформации, виАеостуАия ВГУЭС.

\author{
E.N. Kalinichenko \\ Far Eastern Federal University \\ Vladivostok. Russia
}

\section{Use of video information in the corporate communication system of VVSU}

The article is devoted to the issue of ensuring the corporate interests of Vladivostok State University of Economics and Service (VVSU) by developing the quality of using video information in the system of corporate communication of the very University. Such actions will improve the image of the University as one of the

Калиниченко Евгения Николаевна - магистрант; Дальневосточный федеральный университет; e-mail: Zhenya_ka@mail.ru.

Kalinichenko Evgenia Nikolaevna - graduate student. 
leading universities in the Primorye Territory and more effectively cover all the important for the University classroom groups. Today, thanks to the development of technology, the range of organizations that have corporate TV is expanding. However, despite the relevance of corporate television, the issue of using video information in the corporate communication system is still insufficiently studied. Since video information has its own peculiarities, it makes sense to talk about it.

The purpose of this study is to analyze the use of video information in a corporate communication system using the example of VVSU. The object of the study is the corporate communication of VVSU, and the subject of study is the use of video information in corporate communications of VVSU. Deduction, observation, comparison, analysis, classification and generalization are chosen by the main methods of investigation. As a result, the analysis showed that the university uses all the video information to inform not only the internal community, but also the external one. When creating video materials use a variety of audiovisual means of expressiveness. The information is easily perceived by the viewer, inspires his confidence and sense of presence on the site of the event. It successfully strengthens the image of the university, promotes educational services, being an important, integral and effective part of the corporate information system. Preference is given to news stories. However, the shortcomings in the organizational activity of the university influence the work of corporate television and, as a result, to maximize the productive use of video information. To improve the efficiency of video information use, it is necessary to eliminate these problems; to think over, systematize and structure the broadcasting grid; diversify the program and genre palette; add an entertainment segment. This information can be used by TV journalists, PR specialists, to become a base for course and diploma work.

Keywords: corporate television, image, communication, use of video information, video studio VVSU.

В XXI веке, во время так называемой информационной цивилизации, видам коммуникации уделяется повышенное внимание, что вполне объяснимо. Без коммуникаций практически невозможно распространение информации, становление эффективной организационной деятельности, достижение корпоративных целей, да и просто элементарное существование организованной группы людей. Поэтому сегодня, чтобы успешнее продвигать свои товары (услуги), многие компании тщательно занимаются разработкой своих коммуникационных стратегий и прибегают к такому виду коммуникации, как корпоративная.

Корпоративная коммуникация реализуется в большей степени посредством корпоративных медиа и корпоративных средств массовой информации (СМИ), которые в отличие от деловых СМИ занимаются исключительно интересами конкретной компании. При этом корпоративные СМИ не стремятся напрямую побудить читателя (зрителя) к покупке товаров (услуг), а используют в сравнении с рекламными СМИ более тонкий и сложный коммуникационный инструмент [1, с. 105].

Под корпоративными медиа автор подразумевает всю совокупность технологических средств и приемов, используемых для передачи информационного сообщения конкретному потребителю в том или ином виде, а под корпоративными СМИ - только официально зарегистрированные средства массовой информации. Таким образом, корпоративные СМИ - это «периодическое печатное издание, радио-, теле-, видеопрограмма, интернет-сайт, интернет-портал или иная форма периодического распространения информации, служащая интересам определенной корпорации, созданная по ее инициативе и предназначенная, как правило, для людей, имеющих определенное отношение к данной корпорации» [4, с. 6].

Так, одним из эффективных видов корпоративных СМИ является корпоративное телевидение. Оно обладает теми же преимущественными особенностями информации, что и «большое телевидение»: конкретностью, образностью, нагляд- 
ностью, относительной оперативностью, простотой восприятия, персонификацией информации. Список не является конечным и вполне может быть продлен. Однако перечисленные особенности видеоинформации явно выделяют корпоративное телевидение из других медиа.

Стоит отметить, что на российском корпоративном медиарынке «корпоративное телевидение и радио встречаются намного реже, так как требуют существенных финансовых и материальных ресурсов при значительно меньшей аудитории» [2, с. 32], но все же встречаются, и их количество, начиная с середины девяностых, постепенно растет. Так, к примеру, с 1990 года функционирует корпоративное телевидение АВТОВАЗа в Тольятти. В 1996 году Магнитогорский металлургический комбинат (ММК) создаёт телекомпанию «ТВ-ИН» с собственным вещанием. В 2003 году корпоративное телевидение появляется у титаномагниевого комбината АВИСМА в Пермском крае. Более шестнадцати лет на базе «Газпром добыча Ямбург» существует корпоративное телевидение «Ямбург ТВ», адресованное не только жителям поселков Ямбург и Новозаполярный, но и горожанам Нового Уренгоя. В 2009 году свидетельство о регистрации СМИ получил корпоративный канал крупной транспортной компании - ОАО «Российские железные дороги». В 2005 году оператор связи «Корбина Телеком» создал собственную еженедельную новостную передачу «Corbina News». В 2006 году внутреннее телевидение появилось в томской воспитательной колонии № 2. В 2007 году ростовский фитнес-клуб обзавелся своим клубным каналом «i Well TV», ориентированным на аудиторию в две тысячи зрителей, состоящую из клиентов и сотрудников клуба [3, с. 136].

Из примеров видно, что корпоративные телекомпании стали появляться и развиваться сначала на крупных производствах: градообразующих предприятиях, или же на базе ведущих сырьевых и перерабатывающих корпораций, а с развитием информационных технологий в круг собственников телекомпаний стали включаться и средние организации. Образовательные учреждения не стали исключением. Однако, несмотря на актуальность корпоративного телевидения, вопрос использования видеоинформации в системе корпоративной коммуникации все еще остается недостаточно изученным.

Целью данного исследования является анализ использования видеоинформации в системе корпоративной коммуникации на примере Владивостокского государственного университета экономики и сервиса (ВГУЭС).

Для достижения данной цели были поставлены следующие задачи:

- изучить научную литературу о корпоративном телевидении;

- освоить опыт практиков, занимающихся созданием корпоративной видеоинформации ВГУЭС;

- определить, какую роль играет видеоинформация в системе корпоративной коммуникации;

- проанализировать использование видеоинформации;

- оформить результат исследования в виде рекомендаций вузу, направленных на повышение эффективности использования видеоинформации. 
Объектом исследования является корпоративная коммуникация ВГУЭС, в качестве предмета изучения рассматривается использование видеоинформации в корпоративной коммуникации ВГУЭС.

Дедукция, наблюдение, сравнение, анализ, классификация и обобщение выбраны основными методами исследования.

История ВГУЭС началась с 1967 года. Сегодня кроме головного вуза он включает три филиала, прогимназию, школы, колледжи и представительства Института заочного и дистанционного управления (ИЗДО) [7], расположенные на территориях края. Поэтому для выстраивания эффективных отношений с внутренней и внешней общественностями вуз использует разные виды корпоративных медиа, включая корпоративное телевидение «Видеостудия ВГУЭС», оснащенное современным техническим оборудованием и имеющее свои преимущества перед остальными корпоративными медиа, к примеру, такие, как персонификация информации; простота восприятия; способность вызвать у зрителя эффект доверия и т.д.

Под корпоративным телевидением ВГУЭС автор понимает теле-, видео-, кинохроникальную программу как совокупность периодических аудиовизуальных сообщений и материалов, имеющих постоянное название и выходящих в эфир шесть дней в неделю в формате HD, создаваемых университетом самостоятельно с целью трансляции и воспроизводства корпоративной культуры и, ориентированных на достижение баланса интересов между университетом и его аудиториями.

Как показал анализ контента, всю видеоинформацию ВГУЭС можно разбить на два основных блока: информация, ориентированная на внешнюю аудиторию, и информация, ориентированная на внутреннюю аудиторию.

Видеоматериалы, используемые для информирования внешней аудитории (партнеров, коллег, клиентов), как правило, формируют имидж университета в глазах клиентов, рассказывают об уникальных образовательных программах вуза, особенностях университета, условиях проживания и обучения, то есть объясняют клиенту, почему он должен отдать предпочтение именно этому вузу.

Видеоматериалы, используемые для информирования внутренней аудитории (сотрудников, студентов), содержат информацию о прошедших или предстоящих мероприятиях университета, результатах конкурсов, успехах преподавателей и студентов. Другими словами, они направлены на сокращение дистанции между руководством, сотрудниками и студентами.

Чтобы подача информации была интересной и легко воспринимаемой, журналист «Видеостудии ВГУЭС» использует разные жанры. Выбор жанра зависит от выполняемых задач. Так, наибольшее по объему место в контенте корпоративного телевидения ВГУЭС занимают жанры информационной журналистики. При создании видеоматериалов приоритет отдается новостным сюжетам, так как именно им свойственна новизна и социальная значимость. Большинство новостных сюжетов имеют развернутую структуру: включают различные детали и подробности. Новостную видеоинформацию используют для освещения участия студентов в общественнозначимых событиях для вуза, города и страны, для освещения мероприятий и форумов, проходящих на базе ВГУЭС и за его пределами. Как 
правило, в новостях демонстрируют достижения студентов ВГУЭС в молодежных объединениях студенческого самоуправления, в научных сообществах, в волонтерском центре, студотрядах, вожатских и творческих коллективах и спортивных командах. Это делается с целью выделения активной молодежи вуза и привлечения в университетские сообщества первокурсников.

Кроме жанров информационной журналистики в контенте представлены жанры аналитической журналистики, чаще всего это видеокомментарии представителей органов власти. Видеокомментарии в основном используют для разъяснения какого-либо актуального общественно-политического события. Комментарий можно разместить и в печатном виде, но тогда исчезнут простота восприятия, персонификация, образность и наглядность, присущие видеоинформации, следовательно, уменьшится процент доверия аудитории к полученной информации.

Несмотря на изобилие новостных жанров, в контенте видеоинформации встречаются жанры художественно-публицистической журналистики. Их немного: к примеру, зарисовки в формате видовых съёмок университета. Такое видео отличает художественность операторской работы, где строго выверена композиция каждого кадра, тщательно выбран ракурс, присутствует выразительность световой тональности и так далее. Видовые съёмки часто используются в рекламных целях, чтобы наглядно показать потенциальным клиентам и партнерам университета удобное и доступное расположение вуза.

Следующий жанр - документальное кино [6]. Его основу составляют съемки подлинных лиц и событий. Часто документальные фильмы показывают в качестве агитационного материала в «День открытых дверей» или во время поездок по городам и странам с целью привлечения абитуриентов. Видеофильмы позволяют быстро и наглядно, как никакой другой медиаинструмент, продемонстрировать абитуриентам и их родителям все выигрышные стороны вуза и завоевать симпатию со стороны будущих студентов.

Таким образом, жанровая палитра, используемая журналистом, вполне разнообразна, однако в контенте полностью отсутствуют жанры развлекательного сегмента. Такое положение вещей отрицательно сказывается на интересе студентов к видеоинформации, при том, что студенты - основная целевая группа, их интересы необходимо учитывать, прежде всего.

Стоит отметить и тот факт, что сегодня, благодаря развитию технологий, материалы видеостудии информируют общественность и за пределами университета. В качестве каналов выступают государственные и местные телекомпании, наружные мониторы, корпоративные мобильные приложения и социальные сети, такие, как Facebook, ВКонтакте, Instagram, Twitter, YouTube.

Так, для размещения видеоинформации вполне подходит хостинг YouTube. Отправлять на него видео технически просто, при этом не требуются дополнительные затраты на приобретение дорогостоящего оборудования. Весь контент, размещенный в YouTube, благодаря возможностям портала, тематически структурирован по следующим группам: выступление ректора или президента ВГУЭС; информация абитуриенту; учеба и практика студентов; конкурсы и фестивали; 
наука; студенческая жизнь; культура и искусство; спорт; мода, красота, стиль; форумы, конференции, собрания и встречи [8]. Классификация по плейлистам и техническая доступность облегчают поиск материала: пользователь в любое удобное для него время может зайти на официальную страницу ВГУЭС, выбрать тематическую группу, открыть ее, найти необходимую видеоинформацию и посмотреть сюжет в режиме онлайн в хорошем качестве. При этом, согласно трехлетним наблюдениям автора, с доступностью контента внутри вуза из-за целого ряда причин дела обстоят иначе.

Перед тем как приступить к описанию причин, мешающих эффективному использованию видеоинформации для установления продуктивных диалогических отношений ВГУЭС с аудиториями на территории университета, отметим, что основная деятельность вуза, прежде всего, образовательная. И именно на нее направлено все внимание руководства и материальные ресурсы. Корпоративные коммуникации, безусловно, важны, однако это всего лишь инструменты, способствующие продвижению основной деятельности и повышению ее качества. Поэтому, несмотря на важность корпоративных коммуникаций, руководство все же допускает некую долю экономии в этой сфере. Что постепенно сказывается на производственном процессе видеостудии и, следовательно, на количестве выпускаемой видеопродукции.

Так, в отличие от четко структурированных новостных программ государственных телеканалов, где ведущий с поставленной дикцией за считанные минуты выдает блок новостей, университетские новостные выпуски имеют существенное отличие. К примеру, сюжеты не собраны в блоки, а подаются как самостоятельный продукт с фирменной заставкой и авторским представлением в конце. Поскольку ведущий не предусмотрен в составе коллектива видеостудии, то подводка изначально включена в текст сюжета. Фирменная обчитка - размеренная, неторопливая. Хронометраж неограничен и может доходить до семи минут. Закадровый текст сопровождается музыкальным оформлением.

Такая форма подачи возникла из-за нехватки трудового ресурса и, как следствие, рабочего времени. К примеру, на создание полноценного сюжета на съемку, запись комментариев, написание текста, озвучку, монтаж и просчет журналист и оператор тратят не менее пяти часов. Бывают дни, когда оператор снимает до пяти мероприятий в день. Но вместо пяти материалов на экран успевают выпустить только один. Остальные делают позже. Готовый видеоматериал тут же ставят в эфирную сетку. С такой спецификой работы не представляется возможным систематизировать точное время обновления видеоинформации. Поэтому сетка вещания абсолютно не продумана и лишена всякой структуризации. Кроме того, каждый загруженный в сетку материал имеет свой порядковый номер. Количество видеоматериалов зависит от объема жесткого диска. В настоящее время в течение суток поочередно крутятся не менее восьмидесяти материалов. Но узнать пользователю, когда будет нужная ему видеоинформация, невозможно, что отрицательно сказывается на интересе целевой аудитории. Отсутствие в программном разнообразии развлекательного сегмента и нерегулярное обновление контента также 
имеют свое негативное влияние. Так, к примеру, в сравнении с Южно-Уральским государственным университетом (ЮУрГУ), который при работе полноценной, правда, студенческой команды за март 2018 года на свой сайт в YouTube [9] выложил 81 видеоматериал, ВГУЭС на свою страницу в YouTube за тот же период - только 9, хотя и в более высоком качестве [8].

Отрицательно на эффективном использовании информации сказывается и тот факт, что трансляция видеоинформации в фойе, в местах отдыха и питания становится все больше фоновой, меньше информативной и чаще беззвучной, так как телевизоры, размещенные в фойе и в столовой, мешают охране и работникам общепита. В результате они выключают звук, а порой и сами телевизоры. Вопрос о переносе телевизоров в другие места не раз ставился перед руководством сотрудниками «Видеостудии ВГУЭС», но по сей день так и не решен.

Стоит добавить, что корпоративное телевидение, созданное на базе вуза одиннадцать лет назад, сегодня обслуживается всего лишь двумя сотрудниками. Кроме корпоративных PR-сюжетов и PR-фильмов они производят, в том числе, и рекламную видеопродукцию (рекламные ролики, объявления), которая также успешно помогает укреплять имидж университета и размещается, как правило, в кинотеатрах, на телеканалах и наружных мониторах.

Не стоит забывать о том, что видео, отснятое оператором ВГУЭС, используют государственные и местные телеканалы. Бывают моменты, когда телекомпания желает осветить мероприятие, проходящее на базе университета, а отправить съемочную группу не может. Тогда происходит заимствование кадров у вуза. При подаче видеоинформации на экраны телекомпания осознанно замалчивает имя «ВГУЭС», но зрители все равно понимают, о каком университете идет речь. Так происходит масштабный бесплатный пиар.

Кроме этого, зачастую распространителями видеоинформации о ВГУЭС являются и сами участники мероприятий, к примеру, студенты просят кадры у работников видеостудии для портфолио, затем загружают их в социальные сети, тем самым тиражируя информацию о вузе.

Таким образом, видеоинформация, производимая корпоративным телевидением ВГУЭС, представляет мощное идеологическое оружие вуза, способное охватить большие аудиторные группы, оно не существует обособлено, а гармонично входит в состав корпоративных медиа университета и способствует успешному продвижению вузом своих интересов и информированию общественностей, особенно в последние десять лет, когда на рынке образовательных услуг царствует жесткая конкуренция. В результате за последние одиннадцать лет вуз ни разу не проиграл наборную кампанию. Наоборот, в 2017 году ряды ВГУЭС пополнили первокурсники из 42 субъектов РФ и 7 зарубежных стран [10], что говорит о популярности и узнаваемости вуза не только на территории города, но и за его пределами. Благодаря развитию технологий и грамотному использованию вузом особенностей видеоинформации абитуриент, не выходя из дома, имеет возможность своими глазами увидеть, что происходит в университете, в каких условиях живут студенты, как они проводят свой досуг и так далее, что положительно сказывается на 
популяризации ВГУЭС. Об этом свидетельствуют цифры, взятые из материалов, размещенных на официальных сайтах вузов. Так, в сравнении с Дальневосточным государственным техническим рыбохозяйственным университетом (Дальрыбвтуз) (схожим со ВГУЭС покрываемой площадью квадратных метров, но не имеющим корпоративного телевидения) во ВГУЭС в 2017 году поступили 1000 первокурсников [10], в Дальрыбвтуз - 637 [5].

Выявленные и озвученные ранее автором проблемы в организационной деятельности вуза влияют на производственный процесс видеостудии, на количество выпускаемой продукции, на максимально-продуктивное использование видеоинформации и в результате снижают эффект синергии.

Учитывая эти особенности в работе корпоративного телевидения ВГУЭС, мы можем говорить, что Владивостокскому государственному университету экономики и сервиса, по мнению автора, необходимо обратить внимание на следующие моменты функционирования корпоративного телевидения с целью повышения эффективности использования видеоинформации:

- установить телевизоры так, чтобы они были в поле зрения студентов и сотрудников и не мешали рабочему персоналу;

- следить за качеством звука и изображения;

- систематизировать и структурировать сетку вещания, учитывая время учебы и отдыха студентов;

- разнообразить программную и жанровую палитру, добавить развлекательный сегмент, чтобы аудитория была заинтересована в просмотре;

- пересмотреть форму подачи видеоинформации;

- ежедневно выпускать в эфир свежую новостную информацию;

- увеличить штат сотрудников, возможно, за счет привлечения студентов из Высшей школы телевидения ВГУЭС на взаимовыгодных условиях;

- закупить дополнительное оборудование.

1. Мурзин Д.А. Феномен корпоративной прессы. М.: Хроникер, 2005. 192 с.

2. Серебряков С. Самиздат в фирменной упаковке // Советник. 2003. № 8. С. 30-55.

3. Сидорова Т.И. Телевидение компании как эффективный канал корпоративной коммуникации // Вестник Челябинского государственного университета. Сер.: «Филология. Искусствоведение». 2010. Вып. 47. № 29 (210). С. 136-139.

4. Чемякин Ю.В. Корпоративные СМИ: секреты эффективности. Екатеринбург: Дискурс Пи, 2006. 11 с.

5. В Дальрыбвтузе стартовал учебный год [Электронный ресурс]. URL: http://dalrybvtuz. ru/news/2017-09-01-dalrybvtuz-vstretil.htm.

6. Документальный фильм о ВГУЭС [Электронный pecypc]. URL: https://youtu.be/ cSCcLcLe_yY.

7. Официальный сайт ВГУЭС [Электронный ресypc]. URL:: http://www.vvsu.ru/about/.

8. Официальная страница ВГУЭС в YouTube [Электронный pecypc]. URL: https://www. youtube.com/channel/UCeEmjg78A_gcLFPghNjDlFw. 
9. Официальная страница ЮУрГУ в YouTube [Электронный ресурc]. URL: https://www. youtube.com/channel/UCHPBbFncaCIur8t3O4RmxHA/videos.

10. Посвящение в студенты ВГУЭС 2017: как это было [Электронный ресурc]. URL: http:// www.vvsu.ru/latest/article/2145433892/posvyashchenie_v_studenty_vgues.

\section{Транслитерация}

1. Murzin D.A. Fenomen korporativnoi pressy. M.: Khroniker, 2005, 192 p.

2. Serebryakov S. Samizdat v firmennoi upakovke, Sovetnik, 2003, No 8, pp. 30-55.

3. Sidorova T.I. Televidenie kompanii kak effektivnyi kanal korporativnoi kommunikatsii, Vestnik Chelyabinskogo gosudarstvennogo universiteta, ser. Filologiya. Iskusstvovedenie, iss. 47, 2010, No 29 (210), pp. 136-139.

4. Chemyakin Yu.V. Korporativnye SMI: sekrety effektivnosti. Ekaterinburg: Diskurs Pi, 2006, 11 p.

5. V Dal'rybvtuze startoval uchebnyi god. URL: http://dalrybvtuz.ru/news/2017-09-01dalrybvtuz-vstretil.htm.

6. Dokumental'nyi fil'm o VGUES. URL: https://youtu.be/cSCcLcLe_yY.

7. Ofitsial'nyi sait VGUES. URL: http://www.vvsu.ru/about/.

8. Ofitsial'naya stranitsa VGUES v YouTube. URL: https://www.youtube.com/channel/ UCeEmjg78A_gcLFPghNjDlFw.

9. Ofitsial'naya stranitsa YuUrGU v YouTube. URL: https://www.youtube.com/channel/ UCHPBbFncaCIur8t3O4RmxHA/videos.

10. Posvyashchenie v studenty VGUES 2017: kak eto bylo. URL: http://www.vvsu.ru/latest/

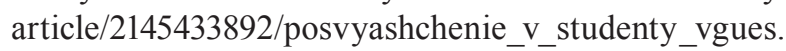

\section{(C) Е.Н. Калиниченко, 2018}

Для цитирования: Калиниченко Е.Н. Использование видеоинформации в системе корпоративной коммуникации ВГУЭС // Территория новых возможностей. Вестник Владивостокского государственного университета экономики и сервиса. 2018. Т. 10. № 2. С. 92-100.

For citation: Kalinichenko E.N. Use of video information in the corporate communication system of VVSU, The Territory of New Opportunities. The Herald of Vladivostok State University of Economics and Service, 2018, Vol. 10, No 2, pp. 92-100.

DOI dx.doi.org/10.24866/VVSU/2073-3984/2018-2/092-100

Дата поступления: 7.05.2018. 